\title{
Impact of Coronavirus Disease 2019 (COVID-19) on College and University Students: A Global Health and Education Problem
}

\author{
Steward Mudenda ${ }^{1,2 *}$, Annie Zulu ${ }^{3}$, Maureen Nkandu Phiri ${ }^{1}$, Moses Ngazimbi ${ }^{1}$, Webrod Mufwambi ${ }^{1}$, \\ Maisa Kasanga ${ }^{4}$, Michelo Banda ${ }^{1}$
}

\author{
${ }^{1}$ The University of Zambia, School of Health Sciences, Department of Pharmacy, P.O Box 50110, Lusaka, ZAMBIA \\ ${ }^{2}$ The University of Zambia, School of Veterinary Medicine, Department of Disease Control, P.O Box 32379, Lusaka, ZAMBIA \\ ${ }^{3}$ Levy Mwanawasa University Teaching Hospital, Department of Pharmacy, P.O Box 37084, Lusaka, ZAMBIA \\ ${ }^{4}$ Zhengzhou University, College of Public Health, 100 Kexue Avenue, Zhengzhou, Henan 450001, CHINA \\ *Corresponding Author: freshsteward@gmail.com
}

Citation: Mudenda, S., Zulu, A., Phiri, M. N., Ngazimbi, M., Mufwambi, W., Kasanga, M. and Banda, M. (2020). Impact of Coronavirus Disease 2019 (COVID-19) on College and University Students: A Global Health and Education Problem. Aquademia, 4(2), ep20026. https://doi.org/10.29333/aquademia/8494

\section{ARTICLE INFO}

Received: 9 Jun. 2020

Accepted: 12 Jul. 2020

\begin{abstract}
The origin of the coronavirus disease 2019 (COVID-19) in Wuhan China has been reported to be one of the lethal pandemics the world has ever faced. Though the first case was reported in December 2019, COVID-19 spread so rapidly to the majority of countries by March 2020 and was declared a global pandemic by the World Health Organization. COVID-19 pandemic led to increased morbidity and mortality within a very short period of time. COVID-19 pandemic caused schools, colleges, and universities to come to a closure in order to avoid further transmission and spread of the disease. The physical closure of schools, colleges, and universities has impacted students in several ways in that some students have reported suffering from anxiety, depression, and mood swings. COVID-19 has disrupted social interaction among students and has affected their family life. These impacts on students will eventually affect their academic performance and progression. Thus, learning institutions should put in measures to help students recover from the impacts of COVID-19.
\end{abstract}

Keywords: Coronavirus disease 2019, colleges, impacts, mental health, schools, universities

Coronavirus disease 2019 (COVID-19) is a global health problem that was first reported in December 2019 (WHO, 2020). COVID-19 is a respiratory tract infection that is caused by severe acute respiratory syndrome coronavirus 2 (SARSCoV-2) and originated from Wuhan, China (Mudenda, 2020; Phiri et al., 2020). Due to the rapid spread and increased morbidity and mortality caused by COVID-19, colleges and universities were closed to prevent the further spread of the SARS-CoV-2. The physical closure of colleges and universities promotes social distancing and staying at home but has impacted students in several ways. Some of the impacts that have emerged due to COVID-19 include impacts on mental health, academic performance, individual and family economy, academic progression, family life, and social networks (Cao et al., 2020; Zhai \& Du, 2020).

Some students reported that the COVID-19 pandemic has made them suffer from mental health disorders. In China, students reported that they experienced mild, moderate, and severe anxiety due to the COVID-19 epidemic (Cao et al., 2020). COVID-19 can contribute to the worsening of preexisting mental health conditions, mainly due to school closures, loss of routine, and restricted social connections
(YoungMinds, 2020). Most youths are now paying more attention to mental health, resting a lot, and exercising frequently which may positively improve their mental health (Liang et al., 2020). These impacts may affect the academic performance of the students because mental health is highly associated with a student's academic performance. It is therefore important that colleges and universities should put in place mental health experts to help their students recover from the mental health impacts of COVID-19. These mental health experts should be stationed in college and university health facilities.

The academic performance of learners is expected to reduce as a result of COVID-19 (Sintema, 2020). In India, a low score in the final examinations is expected from students as the learning has been affected and there is a huge gap between the lessons that students are taught and their final examinations (Gupta \& Goplani, 2020). To mitigate this problem, online learning was introduced which unfortunately, may not be effective for lectures meant meant for face-to-face interaction, laboratory tests and practical work (Sahu, 2020). In addition, for some students whose access to the internet is limited or has problems with internet connectivity, they are 
highly disadvantaged and this in turn adversely affects their grade point average (GPA) (Alruwais et al., 2018). Some students reported that they do not have laptops or gadgets to use for online learning (Sahu, 2020). One study reported that college and university students are stressed about dormitory evacuation and cancellation of anticipated events such as exchange studies and graduation ceremonies (Lee, 2020). Overall, not all colleges and universities can offer online learning effectively, hence, this impact will be felt by a good number of students (Sahu, 2020). Colleges and universities should, therefore, put in measures that will salvage the impact of COVID-19 on the academic performance and progression of the students.

COVID-19 affects the social and family life of students. Due to COVID-19, the majority of the youths have reported receiving increased social support from families and friends (Zhang et al., 2020). However, the minority of the youths felt that they received less social support from their families and friends which may in turn affect their academic life.

In Zambia, schools, colleges, and universities were closed on the $20^{\text {th }}$ of March 2020. Students who have problems with internet connectivity or have limited access to the internet will be highly disadvantaged, a situation that can adversely affect their grade point average and academic progression. It is important that learning institutions should take into consideration the impacts of COVID-19 on the learners and consider remedial measures (Cao et al., 2020).

We, therefore, recommend that colleges and universities must provide relevant psychological counselling measures to help students recover from the impact of COVID-19. In addition, colleges and universities should consider using their online platforms to upload information on coping with COVID-19 so that students can have access to such information.

In conclusion, schools, colleges, and universities should put in place some strategies that will help their students cope with the impacts of COVID-19. Students should adapt to online education and involve themselves in activities that will improve their mental health.

\section{REFERENCES}

Alruwais, N., Wills, G., \& Wald, M. (2018). Advantages and Challenges of Using e-Assessment. Int. J. Inf. Educ. Technol, 8(1), 34-37. https://doi.org/10.18178/ijiet.2018.8.1.1008
Cao, W., Fang, Z., Hou, G., Han, M., Xu, X., Dong, J., \& Zheng, J. (2020). The psychological impact of the COVID-19 epidemic on college students in China. Psychiatry Research, 287, 112934. https://doi.org/10.1016/j.psychres.2020. 112934

Gupta, A., \& Goplani, M. (2020). Impact of Covid-19 on Educational Institutions in India. UGC Care J, 31, 661-671.

Lee, J. (2020). Mental health effects of school closures during COVID-19. The Lancet Child \& Adolescent Health, 4(6), 421. https://doi.org/10.1016/S2352-4642(20)30109-7

Liang, L., Ren, H., Cao, R., Hu, Y., Qin, Z., Li, C., \& Mei, S. (2020). The Effect of COVID-19 on Youth Mental Health. Psychiatr Q. Published: 21 April 2020. https://doi.org/10.1007/s11126-020-09744-3

Mudenda, S. (2020). Coronavirus Disease (COVID-19): A Global Health Problem. Int J Pharm Pharmacol, 4, 141. https://doi.org/10.31531/2581-3080.1000141

Phiri, M. N., Banda, M., Mudenda, S., et al. (2020). Coronavirus Disease 2019 (COVID-19): The Role of Pharmacists in the Fight against COVID-19 Pandemic. Int J Pharm Pharmacol, 4, 143. https://doi.org/10.31531/2581-3080.1000143

Sahu, P. (2020). Closure of Universities Due to Coronavirus Disease 2019 (COVID-19): Impact on Education and Mental Health of Students and Academic Staff. Cureus, 12(4), e7541. https://doi.org/10.7759/cureus.7541

Sintema, E. J. (2020). Effect of COVID-19 on the Performance of Grade 12 Students: Implications for STEM Education. Eurasia Journal of Mathematics, Science and Technology Education, 16(7), em1851. https://doi.org/10.29333/ejmste/ 7893

World Health Organization, World Health Organization. (2020). Report of the WHO-China joint mission on coronavirus disease 2019 (COVID-19). Retrieved from https://www.who.int/docs/default-source/coronaviruse/ who-china-joint-mission-on-covid-19-final-report.pdf

YoungMinds. (2020). Coronavirus: Impact on young people with mental health needs. https://youngminds.org.uk/ media/3708/coronavirus-report_march2020.pdf

Zhai, Y., \& Du, X. (2020). Addressing collegiate mental health amid COVID-19 pandemic. Psychiatry Research, 288, 113003. https://doi.org/10.1016/j.psychres.2020.113003

Zhang, Y., \& Ma, Z. F. (2020). Impact of the COVID-19 Pandemic on Mental Health and Quality of Life among Local Residents in Liaoning Province, China: A CrossSectional Study. Int. J. Environ. Res. Public Health, 17, 2381. https://doi.org/10.3390/ijerph17072381 